\title{
AVALIAÇÃo DA PRODUÇÃO DE $\beta$-GLICOSIDASE PELA LINHAGEM DE ASPERGILLUS NIGER LBA O2 EM MEIO SEMISSÓLIDO UTILIZANDO RESÍDUOS AGROINDUSTRIAIS, EXTRATO DE LEVEDURA E SAIS, POR MEIO DA FERRAMENTA DE PLANEJAMENTO EXPERIMENTAL
}

\author{
J. A. FIGUEIRA ${ }^{1}$, F.F.G. DIAS ${ }^{1}$ e H.H. SATO ${ }^{1}$ \\ ${ }^{1}$ Universidade Estadual de Campinas, Departamento de Ciência de Alimentos \\ E-mail para contato: joangelotti@gmailcom
}

\begin{abstract}
RESUMO As $\beta$-glicosidases são enzimas que hidrolisam ligações $\beta$-glicosídicas em aril, amino ou alquil - $\beta$-D-glicosídeos, glicosídeos cianogênicos, oligo e dissacarídeos. Este trabalho teve como objetivo avaliar a produção da enzima $\beta$-glicosidase pela linhagem de Aspergillus niger LBA 02 utilizando como substratos os resíduos agroindustriais, casca de maracujá, bagaço de cana-de-açúcar e farelo de trigo, com intuito de minimizar os custos de produção da enzima e estudar o efeito da adição de sais e extrato de levedura no meio semissólido através da ferramenta de planejamento experimental. A adição de bagaço de canade-açúcar e de casca de maracujá, no meio contendo farelo de trigo, não resultou em aumento da produção de $\beta$-glicosidase indicando que não atuaram como indutores da enzima, nas faixas estudadas. A adição de $0,1 \%$ de extrato de levedura e $0,2 \%$ de $\mathrm{KH}_{2} \mathrm{PO}_{4}, 0,2 \%$ de $\mathrm{NH}_{4} \mathrm{NO}_{3} \mathrm{e}$ $0,1 \%$ de $\mathrm{MgSO}_{4} .7 \mathrm{H}_{2} \mathrm{O}$ no meio semissólido de farelo de trigo, não tiveram efeitos significativos no aumento da produção de $\beta$-glicosidase, nos níveis estudados. Na fermentação da linhagem de A. niger LBA 02 em frascos Erlenmeyer de $500 \mathrm{~mL}$ foi obtida maior produção de $\beta$-glicosidase $(44,81 \mathrm{U} / \mathrm{g})$ em meio de cultura composto de $25 \mathrm{~g}$ de farelo de trigo e 5,7 $\mathrm{mL}$ de água destilada, após $240 \mathrm{~h}$ de fermentação a $30^{\circ} \mathrm{C}$. A enzima foi aplicada na conversão de isoflavonas glicosiladas de soja (daidzina e genistina) em suas formas agliconas (daidzeína e genisteína), sendo obtida uma taxa de conversão de quase $100 \%$ após 30 min. de reação a $50^{\circ} \mathrm{C}$.
\end{abstract}

\section{INTRODUÇÃO}

As $\beta$-glicosidases são enzimas que hidrolisam ligações $\beta$-glicosídicas em aril, amino ou alquil - $\beta$-D-glicosídeos, glicosídeos cianogênicos, e oligo e dissacarídeos, liberando o terminal não redutor (Cairns e Esen, 2010). Nos últimos anos, o interesse na $\beta$-glicosidase tem aumentado devido a sua participação nos mais variados processos biotecnológicos, incluindo a aplicação da enzima para formação de compostos de aroma e estabilização de sucos e bebidas, sendo de potencial interesse para a indústria de alimentos e bebidas, para melhoramento das propriedades sensoriais dos produtos (Karnchanatat et al., 2007; Villena, 2007; Palmeri e Spagna, 2007). 


\section{9 a 22 de outubro de 2014 \\ Florianópolis/SC}

A $\beta$-glicosidase é utilizada comercialmente para a transformação de isoflavonas glicosiladas de soja em isoflavonas agliconas daidzeina, genisteina e gliciteina (Matsuura et al., 1989; Park et al., 2001). Estudos revelam que estas isoflavonas agliconas possuem efeitos benéficos à saúde humana (Matsuura et al., 1989; Peterson e Barnes, 1993; Park et al., 2001).

A $\beta$-glicosidase pode ser obtida a partir de leveduras (Saccharomyces cerevisiae, Pichia etchellsii), bactérias (Brettanomyces bruxellensis, Oenococcus oeni e Clostridium thermocellum), fungos mesofílicos (Trichoderma harzianum e Aspergillus sp.), fungos termofílicos (Thermoascus aurantiacus, Chaetomium thermophile, Humicola insolens, Sporotrichum thermophile) e fungos que utilizam hidrocarbonetos (Cladosporium resinae) (Grabnitz e Staudenbauer, 1988; Pandey e Mishra,1997; Iwashita et al., 1998; Van Rensburg et al., 1998; Oh et al., 1999; Maheshwari et al., 2000; Manasfield et al., 2001; Parry et al., 2001; Yun et al., 2001).

O uso da fermentação semissólida tem se mostrado particularmente vantajoso para o crescimento de fungos filamentosos, uma vez que simula o habitat natural destes microorganismos. Essa vantagem é estendida à produção de enzimas, proporcionando uma maior produtividade quando comparada ao processo de fermentação submersa. Além disso, as enzimas produzidas pela fermentação semissólida são menos susceptíveis a problemas de inibição por substrato e também possuem uma estabilidade maior a variações de temperatura e $\mathrm{pH}$ (Holker et al., 2004).

Outra vantagem da fermentação semissólida é a possibilidade de utilização de resíduos agroindustriais como substrato sólido, servindo estes como fontes de carbono e energia. Geralmente são utilizados farelos, bagaços, cascas e palhas como materiais viáveis para biotransformação (Rutz et al., 2008). Estes materiais possuem uma estrutura rica em diversos compostos como celulose, hemicelulose, lignina, amido, pectina e proteínas, sendo bem heterogêneo, e podendo ser utilizado como fonte de carbono e energia como também de suporte para crescimento microbiano (Pandey, 2003).

A casca de maracujá é um produto vegetal rico em fibra do tipo solúvel (pectina e mucilagem). Segundo Córdova et al. (2005) a casca de maracujá é constituída de 4,6\% de proteínas, $0,3 \%$ de extrato etéreo, $26,7 \%$ de fibra bruta e $20 \%$ de pectina. O maracujá contém $\beta$ glicosídeos amigdalina e prunina que podem atuar como indutores da produção de $\beta$-glicosidase.

As matérias-primas lignocelulósicas são fontes renováveis provenientes de materiais agroindustriais, resíduos urbanos e madeiras de angiospermas e gimnospermas. Dentre elas, os materiais agroindustriais se destacam pelo caráter de resíduo, conferido por sua obtenção após o processamento de matérias-primas que apresentam maior valor agregado. No Brasil um grande volume de biomassa é gerado, sendo a maior parte da biomassa gerada constituída por bagaço de cana-de-açúcar (Castro e Pereira Jr, 2010).

Este trabalho visou o estudo da produção da enzima $\beta$-glicosidase por uma linhagem de Aspergillus sp. utilizando como fonte de nutrientes resíduos agroindustriais, com intuito de 
minimizar os custos de produção da enzima e sua aplicação para conversão de isoflavonas glicosiladas em agliconas.

\section{MATERIAIS E MÉTODOS}

\subsection{Manutenção da cultura}

A linhagem do fungo Aspergillus niger LBA 02 da coleção de culturas do Laboratório de Bioquímica de Alimentos da Faculdade de Engenharia de Alimentos, Universidade Estadual de Campinas foi utilizada para a produção de $\beta$-glicosidase. $\mathrm{O}$ fungo foi cultivado em tubos de meio de cultivo Ágar Batata Dextrose (PDA) inclinado, durante 3 dias, a $30^{\circ} \mathrm{C}$. Após incubação adicionou-se vaselina estéril aos tubos de ensaio e as culturas foram mantidas a $5^{\circ} \mathrm{C}$.

\subsection{Pré-inóculo e fermentação da linhagem de Aspergillus niger LBA 02 em meio semissólido de farelo de trigo para a produção de $\beta$-glicosidase}

A cultura da linhagem de Aspergillus niger LBA 02 cultivada em meio inclinado conforme descrito no item acima, foi espalhada em placas de petri contendo Ágar Batata Dextrose com auxílio de um cotonete de algodão esterilizado, e incubado durante 3 dias a $30^{\circ} \mathrm{C}$. Para a fermentação, 15 discos de $10 \mathrm{~mm}$ de diâmetro recobertos com a cultura foram transferidos assepticamente para frascos Erlemeyers de $250 \mathrm{~mL}$ contendo $10 \mathrm{~g}$ de meio de cultivo, previamente esterilizado durante 20 minutos a $121^{\circ} \mathrm{C}$. Os frascos foram incubados a $30^{\circ} \mathrm{C}$ durante 5 dias. O meio fermentado foi utilizado para a produção da $\beta$-glicosidase extracelular.

\subsection{Extração da $\beta$-glicosidase}

A extração da enzima foi feita adicionando-se $50 \mathrm{~mL}$ de água destilada aos frascos Erlenmeyers. Os frascos foram agitados a $150 \mathrm{rpm}$ durante 20 minutos a temperatura ambiente e em seguida as amostras foram filtradas em papel de filtro. $\mathrm{O}$ filtrado foi utilizado como extrato enzimático bruto de $\beta$-glicosidase.

\subsection{Determinação da atividade de $\beta$-glicosidase}

A atividade de $\beta$-glicosidase foi determinada como descrito por Matsuura et al. (1995) com modificações. Uma unidade da atividade enzimática foi definida como a quantidade de enzima necessária para liberar $1 \mu \mathrm{mol}$ de $\rho$-nitrofenol por minuto nas condições do ensaio por grama de meio de cultivo semissólido.

\subsection{Estudo da produção de $\beta$-glicosidase pela linhagem de $A$. niger LBA 02 por planejamento experimental}


2.5.1 Estudo dos efeitos da temperatura e da quantidade de inóculo, água destilada, casca de maracujá, extrato de levedura e sais no meio de cultura semissólido de farelo de trigo para a fermentação de $A$. niger LBA 02 e produção de $\beta$-glicosidase, por planejamento fatorial fracionado $2^{(8-4)}$

Os parâmetros temperatura, quantidade de pré-inóculo, água adicionada ao meio de fermentação semissólida, casca de maracujá, extrato de levedura e adição dos sais $\mathrm{KH}_{2} \mathrm{PO}_{4}$, $\mathrm{NH}_{4} \mathrm{NO}_{3}, \mathrm{MgSO}_{4}$ para a produção da enzima foram estudados através de planejamento fatorial fracionado $2^{(8-4)}$.

O preparo do meio de cultivo foi realizado pesando-se $25 \mathrm{~g}$ de farelo de trigo em um béquer e adicionando-se os componentes estudados nos níveis do planejamento experimental conforme listados na Tabela1.

Tabela 1: Variáveis e níveis estudados no planejamento fatorial fracionário $2^{(8-4)}$

\begin{tabular}{ccccc}
\hline \multirow{2}{*}{ Variável } & \multirow{2}{*}{ Unidade } & \multicolumn{3}{c}{ Níveis } \\
\cline { 3 - 5 } & & -1 & 0 & +1 \\
\hline $\begin{array}{c}\text { Temperatura } \\
\text { Casca de } \\
\text { maracujá }\end{array}$ & $\mathrm{C}$ & 25 & 30 & 35 \\
$\begin{array}{c}\text { Quantidade de } \\
\text { água }\end{array}$ & $\mathrm{g}$ & 12,5 & 25 & 37,5 \\
$\begin{array}{c}\text { adicionada } \\
\text { Quantidade de }\end{array}$ & $\mathrm{N}^{\circ}$ discos* & 10 & & 30 \\
inoculo & $\%$ & 10 & 20 & \\
$\mathrm{KH}_{2} \mathrm{PO}_{4}$ & $\%$ & 0 & 15 & 20 \\
$\mathrm{NH}_{4} \mathrm{NO}_{3}$ & $\%$ & 0 & 0,1 & 0,2 \\
$\mathrm{MgSO}_{4} 7 \mathrm{H}_{2} \mathrm{O}$ & $\%$ & 0 & 0,1 & 0,2 \\
$\begin{array}{c}\text { Extrato de } \\
\text { levedura }\end{array}$ & $\%$ & 0 & 0,05 & 0,1 \\
\hline
\end{tabular}

* Número de discos de $10 \mathrm{~mm}$ de diâmetro de Ágar Batata Dextrose recobertos com a cultura de A. niger LBA 02.

O meio de cultura foi homogeneizado com bastão de vidro e amostras de $10 \mathrm{~g}$ foram transferidas para frascos Erlenmeyers de $250 \mathrm{~mL}$ sendo os frascos esterilizados em autoclave por 20 minutos a $121^{\circ} \mathrm{C}$. Os discos de PDA recobertos com o fungo foram adicionados assepticamente aos frascos Erlenmeyers contendo os meios de cultura e em seguida foram incubados na temperatura estabelecida pelo planejamento por 9 dias. A atividade de $\beta$-glicosidase foi determinada usando-se o substrato $\rho$-NPG como descrito anteriormente. 
2.5.2 Estudo dos efeitos da quantidade de casca de maracujá e da água destilada no meio semissólido de farelo de trigo para a fermentação de $A$. niger LBA 02 e produção de $\beta$-glicosidase, por delineamento composto central rotacional (DCCR) $2^{2}$

Após a seleção das variáveis significativas de acordo com o item acima, realizou-se um delineamento composto central rotacional (DCCR) $2^{2}$, com combinação entre as variáveis independentes (quantidade de casca de maracujá e água destilada) e seus níveis de concentração conforme Tabela 2.

Os experimentos foram realizados através da metodologia de planejamento experimental e análise de superfície de resposta e os dados foram tratados com o auxílio do programa computacional STATISTICA, StatSoft - versão 7.0 ${ }^{\circledR}$ (2325 East 13 th Street, Tulsa, OK, 74104, EUA).

Tabela 2: Valores codificados e reais utilizados no delineamento composto central rotacional $2^{2}$ para o estudo dos efeitos da quantidade de casca de maracujá e água no meio de cultura semissólido de farelo de trigo para fermentação da linhagem de A. niger LBA 02 e produção de

$\beta$-glicosidase

\begin{tabular}{ccccccc}
\hline Variáveis & Unidades & $\mathbf{- 1 , 4 1}$ & $\mathbf{- 1}$ & $\begin{array}{c}\text { Nível } \\
\mathbf{0}\end{array}$ & $\mathbf{1}$ & $\mathbf{1 , 4 1}$ \\
\hline $\begin{array}{c}\text { Casca de } \\
\text { maracujá ou } \\
\text { bagaço de cana } \\
\text { de açúcar }\end{array}$ & $\mathrm{G}$ & 0 & 1,8 & 6,25 & 10,7 & 12,5 \\
Quant. água & $\mathrm{mL}$ & 5 & 5,7 & 7,5 & 9,3 & 10 \\
\hline
\end{tabular}

2.5.3 Estudo dos efeitos da quantidade de bagaço de cana-de-açúcar e água destilada no meio semissólido de farelo de trigo para a fermentação de $A$. niger LBA 02 e produção de $\beta$ glicosidase, por delineamento composto central rotacional (DCCR) $2^{2}$

Foi realizado um delineamento composto central rotacional (DCCR) $2^{2}$, para avaliação dos efeitos das variáveis independentes: quantidade de bagaço de cana-de-açúcar e água destilada (Tabela 2).

Os experimentos foram realizados através da metodologia de planejamento experimental e análise de superfície de resposta e os dados foram tratados com o auxílio do programa computacional STATISTICA, StatSoft - versão 7.0 ${ }^{\circledR}$ ( 2325 East 13 th Street, Tulsa, OK, 74104, EUA).

\subsection{Extração das isoflavonas glicosiladas de soja}

As isoflavonas glicosiladas de soja foram obtidas como descrito por Aguiar (2004) com modificações. O sobrenadante foi utilizado como extrato para determinação do teor de isoflavonas por cromatografia líquida de alta eficiência em fase reversa (CLAE-FR) de acordo 


\section{9 a 22 de outubro de 2014 \\ Florianópolis/SC}

com o método proposto por Park et al. (2002). O extrato também foi utilizado na conversão de isoflavonas glicosiladas em isoflavonas agliconas usando $\beta$-glicosidase livre.

\subsection{Conversão de isoflavonas glicosiladas de soja em isoflavonas agliconas usando $\beta$ - glicosidase livre.}

Tubos eppendorf contendo amostras de $1 \mathrm{~mL}$ de extrato de isoflavonas e $0,1 \mathrm{~mL}$ de solução $0,1 \mathrm{mg} / \mathrm{mL}$ de $\beta$-glicosidase (13600 U/g) em tampão acetato $0,1 \mathrm{M} \mathrm{pH} \mathrm{4,5} \mathrm{foram} \mathrm{incubados} \mathrm{em}$ banho maria a $50^{\circ} \mathrm{C}$, sob agitação. Após intervalos de tempo de 0,5; 3 e $24 \mathrm{~h}$ foram retiradas alíquotas para análise da conversão de isoflavonas glicosiladas em isoflavonas agliconas por cromatografia líquida como proposto por Park et al. (2002). O extrato de isoflavonas sem adição da enzima foi utilizado como controle.

\subsection{Determinação de isoflavonas por cromatografia líquida de alta eficiência}

O teor de isoflavonas foi determinado conforme descrito por Aguiar (2004) com modificações, As concentrações foram expressas em $\mu \mathrm{g}$ de isoflavonas por $g$ de farelo de soja, em base seca.

\section{RESULTADOS E DISCUSSÃO}

3.1 Estudo dos efeitos da temperatura e da quantidade de inóculo, água, casca de maracujá, extrato de levedura e sais no meio de cultura semissólido de farelo de trigo para a fermentação de $A$. niger LBA 02 e produção de $\beta$-glicosidase, por planejamento fatorial fracionado $2^{(8-4)}$

A Tabela 3 ilustra os efeitos das variáveis independentes na atividade de $\beta$-glicosidase. De acordo com a análise dos efeitos, pode-se observar que as variáveis quantidade de casca de maracujá e $\mathrm{MgSO}_{4} .7 \mathrm{H}_{2} \mathrm{O}$ apresentaram efeitos negativos e significativos na faixa estudada a um nível de confiança de $95 \%(p<0,05)$. Entretanto, a variável independente quantidade de água adicionada foi incluída para um novo planejamento, pois o $p$-valor estava muito próximo ao limite (considerando confiança de $90 \%, p<0,1$ ) e a variável $\mathrm{MgSO}_{4} \cdot 7 \mathrm{H}_{2} \mathrm{O}$ não foi incluída, pois já havia sido estudada na concentração zero. A variável independente temperatura apresentou efeito negativo sobre a atividade da $\beta$-glicosidase, mas não significativo, sendo fixada no nível (0), na temperatura de $30^{\circ} \mathrm{C}$. A variável independente quantidade de inóculo apresentou efeito positivo, mas não significativo, sendo fixada no nível (-1), com inóculo de 10 discos de meio recobertos com o fungo. E os sais $\left(\mathrm{KH}_{2} \mathrm{PO}_{4}, \mathrm{NH}_{4} \mathrm{NO}_{3}, \mathrm{MgSO}_{4} .7 \mathrm{H}_{2} \mathrm{O}\right)$ e extrato de levedura foram fixados no nível (-1), pois não foram significativos.

Segundo Farinas et al. (2008) a utilização de resíduos agroindustriais para a produção de celulases é muito promissora, porém devem ser estudados mais pré-tratamentos para reduzir a recalcitrância dos resíduos e suplementação do meio de cultura com fontes de carbono mais facilmente assimiláveis com intuito de serem obtidas melhores atividades. 
Tabela 3: Efeitos da temperatura, quantidade de água, inóculo, casca de maracujá, $\mathrm{KH}_{2} \mathrm{PO}_{4}$, $\mathrm{NH}_{4} \mathrm{NO}_{3}, \mathrm{MgSO}_{4} .7 \mathrm{H}_{2} \mathrm{O}$ e extrato de levedura no meio de cultura semissólido de farelo de trigo para fermentação da linhagem de Aspergillus niger LBA 02 e produção de $\beta$-glicosidase, do planejamento fatorial fracionário $2^{(8-4)}$.

\begin{tabular}{lcccc}
\hline \multicolumn{1}{c}{$\mathrm{O}$} & Efeito & Erro padrão & $\mathbf{t}(\mathbf{1 0})$ & $\mathbf{P}$ \\
\hline Média & 23,00 & 2,08 & 11,08 & 0,000001 \\
Temperatura & $-1,31$ & 4,53 & $-0,29$ & 0,778 \\
Casca de maracujá* & $-10,90$ & 4,53 & $-2,41$ & 0,0368 \\
Quant. de água adicionada & $-8,08$ & 4,53 & $-1,78$ & 0,104 \\
Quant. de inoculo & 1,46 & 4,53 & 0,32 & 0,753 \\
$\mathbf{K H}_{\mathbf{2}} \mathbf{P O}_{\mathbf{4}}$ & 1,95 & 4,53 & 0,430 & 0,676 \\
$\mathbf{N H}_{\mathbf{4}} \mathbf{N O}_{\mathbf{3}}$ & 2,06 & 4,53 & 0,45 & 0,658 \\
$\mathbf{M g S O}_{\mathbf{4}} \cdot \mathbf{7} \mathbf{H}_{\mathbf{2}} \mathbf{O}^{*}$ & $-12,40$ & 4,53 & $-2,74$ & 0,021 \\
Extrato de levedura & 1,52 & 4,53 & 0,34 & 0,743 \\
\hline
\end{tabular}

*Parâmetros estatisticamente significativos a 95\% de nível de confiança

\subsection{Delineamento composto central rotacional (DCCR) $2^{2}$ - resíduo casca de maracujá}

Nenhuma das variáveis estudadas teve efeito significativo na produção de $\beta$-glicosidase pela linhagem $A$. niger LBA 02 nos níveis estudados. Nos dois planejamentos, o resíduo casca de maracujá, nas faixas estudadas não induziu a produção da enzima $\beta$-glicosidase, já que nos ensaios que continham somente farelo de trigo e água destilada foram obtidos valores de atividades superiores.

3.3 Estudo dos efeitos da quantidade de bagaço de cana-de-açúcar e de água destilada no meio semissólido de farelo de trigo para a fermentação de $A$. niger LBA 02 e produção de $\beta$-glicosidase, por delineamento composto central rotacional (DCCR) $2^{2}$

A Tabela 4 apresenta os valores de t, p e coeficientes de regressão utilizados para a construção do modelo representativo da atividade de $\beta$-glicosidase a partir das variáveis estudadas.

Tabela 4: Coeficiente de regressão e desvio padrão no estudo dos efeitos da quantidade de bagaço de cana-de-açúcar e água destilada no meio de cultura semissólido de farelo de trigo para a fermentação da linhagem de $A$. niger LBA 02 e produção de $\beta$-glicosidase.

\begin{tabular}{lcccc}
\hline & $\begin{array}{c}\text { Coeficiente } \\
\text { de regressão }\end{array}$ & Erro padrão & $\mathbf{t}(\mathbf{5})$ & p \\
\hline Média* & 27,18 & 1,64 & 16,66 & $<0,001$ \\
Bagaço de cana-de-açúcar $\left(\mathbf{x}_{\mathbf{1}}\right)$ & $-5,99$ & 0,99 & $-5,99$ & 0,002 \\
$(\mathbf{L})^{*}$ & & &
\end{tabular}


Bagaço de cana-de-açúcar $\left(\mathrm{x}_{1}\right)$

(Q)

1,76

$-2,18$

Água destilada $\left(\mathbf{x}_{2}\right)(\mathrm{L})^{*}$

Água destilada $\left(\mathrm{x}_{2}\right)(\mathrm{Q})$

$\mathbf{x}_{1} * \mathbf{X}_{2}$

* parâmetros estatisticamente significativos $(\mathrm{p}<0,10)$
1,19

0,99

1,19

1,41
1,48

$-2,18$

$-1,73$

1,22
0,198

0,080

0,143

0,279

L: parâmetro linear; Q: parâmetro quadrático.

Somente os termos lineares para as variáveis bagaço de cana-de-açúcar e quantidade de água foram significativos, sugerindo que outros níveis devem ser estudados.

A análise de variância (ANOVA) mostrou que $75 \%$ da variação observada nos ensaios foi explicada pelo modelo. O F-valor calculado $(11,76)$ para a regressão foi maior que o $\mathrm{F}$ - tabelado $(3,11)(p=0,004)$ refletindo a significância estatística do modelo. A falta de ajuste não foi significativa.

A equação abaixo representa o modelo linear para o planejamento experimental:

$\mathrm{Y}_{1}=26,96-5,99 \mathrm{x}_{1}-2,18 \mathrm{x}_{2}$

Onde:

$$
\begin{aligned}
& \mathrm{Y}_{1}=\text { Atividade de } \beta \text {-glicosidase }(\mathrm{U} / \mathrm{g}) \\
& \mathrm{x}_{1}=\text { bagaço de cana-de-açúcar }(\mathrm{g}) \\
& \mathrm{x}_{2}=\text { água destilada }(\mathrm{mL})
\end{aligned}
$$

A superfície de resposta e a curva de contorno foram geradas a partir do modelo. A produção de $\beta$-glicosidase por $A$. niger LBA 02 foi maior no meio de cultivo contendo $25 \mathrm{~g}$ de farelo de trigo, 0 a 1,8 g de bagaço de cana-de-açúcar e água destilada na faixa de 5 a 7,5 $\mathrm{mL}$. As duas variáveis apresentaram efeito negativo na atividade de $\beta$-glicosidase.
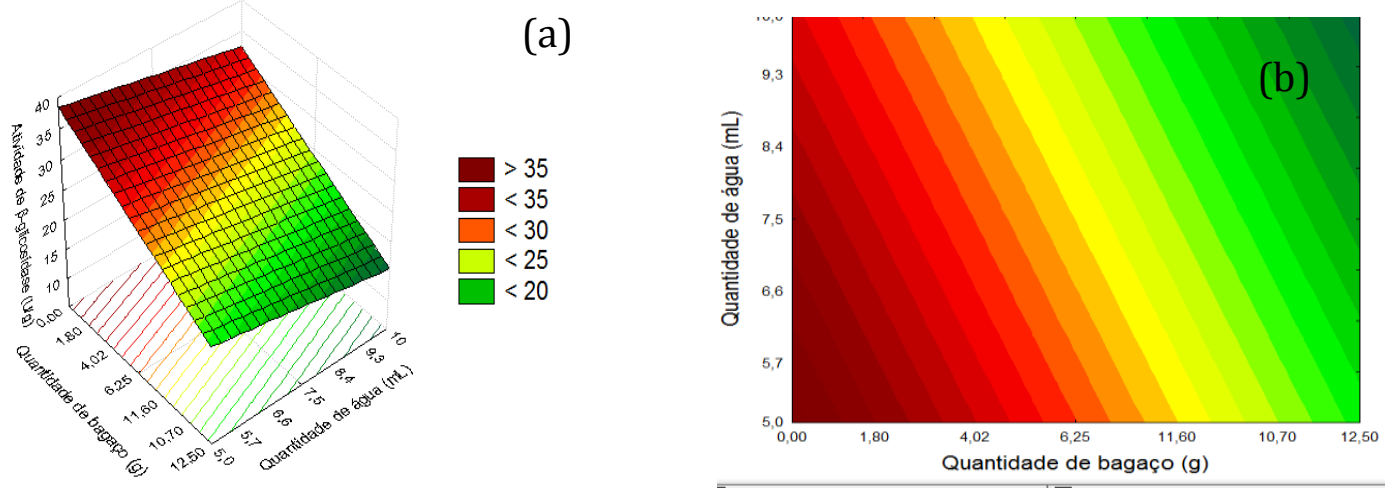

Figura 1: Superfície de resposta (a) e curva de contorno (b) para atividade de $\beta$-glicosidase (U/g) em função da quantidade de bagaço de cana-de-açúcar $(\mathrm{g})$ e quantidade de água destilada $(\mathrm{mL})$ no meio semissólido de farelo de trigo 


\subsection{Conversão de isoflavonas glicosiladas de soja}

A Figura 2, ilustra que a $\beta$-glicosidase livre de A. niger LBA 02 foi capaz de converter quase totalmente as glicosil - isoflavonas daidzina e genistina em suas formas agliconas daidzeína e genisteína, após $0,5 \mathrm{~h}$ de reação a $50^{\circ} \mathrm{C}$.

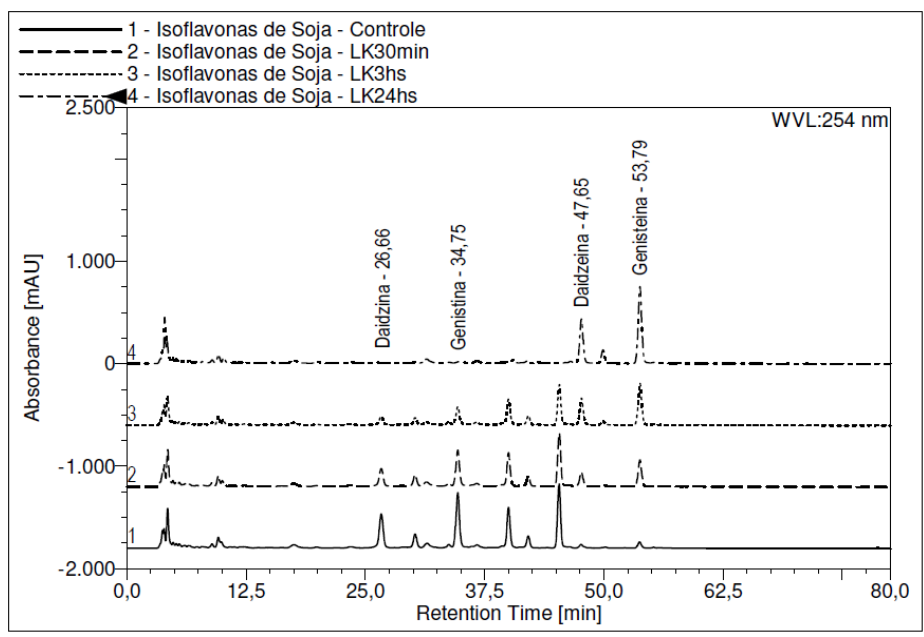

Figura 2: Cromatogramas obtidos por CLAE-DAD a $254 \mathrm{~nm}$ do extrato de isoflavonas de soja controle (cromatograma 1) e dos extratos tratados $\operatorname{com} \beta$-glicosidase imobilizada em lentes PVA - Lentikats ${ }^{\circledR}$ nos tempos 0,5 , 3 e 24 h (cromatogramas 2,3 e 4 ), respectivamente.

No presente trabalho, o teor de daidzeína e genisteína aumentou aproximadamente 2,6 e 11,7 vezes quando aplicada a enzima $\beta$-glicosidase livre, respectivamente, ao final de $24 \mathrm{~h}$.

\section{CONCLUSÃO}

A linhagem Aspergillus sp. LBA 02 foi identificada como Aspergillus niger. A identificação foi realizada de acordo com a chave de classificação de Klich e Pitt.

Foi obtida maior atividade de $\beta$-glicosidase $(44,81 \mathrm{U} / \mathrm{g})$ na fermentação da linhagem $A$. niger LBA 02 em meio semissólido composto por $25 \mathrm{~g}$ de farelo de trigo e $5,7 \mathrm{~mL}$ de água destilada, após $240 \mathrm{~h}$ de fermentação a $30^{\circ} \mathrm{C}$.

Os substratos casca de maracujá e bagaço de cana-de-açúcar moído acrescentados no meio de cultura de farelo de trigo não atuaram como indutores para a produção de $\beta$-glicosidase. E as variáveis temperatura, quantidade de inóculo, extrato de levedura e adição dos sais $\mathrm{KH}_{2} \mathrm{PO}_{4}$, $\mathrm{NH}_{4} \mathrm{NO}_{3}, \mathrm{MgSO}_{4} 7 \mathrm{H}_{2} \mathrm{O}$ no meio semissólido de farelo de trigo, para fermentação de $A$. niger LBA 02, nos níveis estudados no planejamento experimental fracionário $2^{(8-4)}$ não resultaram em aumento da atividade de $\beta$-glicosidase.

$\beta$-glicosidase livre obtida de Aspergillus niger LBA 02 foi capaz de hidrolisar as isoflavonas glicosiladas de soja em isoflavonas agliconas após $0,5 \mathrm{~h}$ de reação a $50^{\circ} \mathrm{C}$. 


\section{REFERÊNCIAS BIBLIOGRÁFICAS}

AGUIAR, C.L. - Transformações físicas e bioquímica de isoflavonas conjugadas de soja (Glycine Max L.) e o efeito na atividade biológica in vittro, Tese (Doutorado em Ciência de Alimentos), Faculdade de Engenharia de Alimentos, Universidade Estadual de Campinas, 2004.

CAIRNS, J.R.K.; ESEN, A. - $\beta$ - glucosidases. Cellular and Molecular Life Sciences, v.67, p. $3389-3405,2010$.

CASTRO, A. M.; PEREIRA JR, N. Produção, propriedades e aplicação de celulases na hidrólise de resíduos agroindustriais. Química Nova [online], v.33, n.1, p. 181-188, 2010.

CÓRDOVA, K.R.V.; GAMA, T.M.M.T.B.; WINTER, C.M.G.; NETO, G.K.; FREITAS, R.J.S. Características físico-químicas da casca do maracujá amarelo (Passiflora edulis Flavicarpa Degener) obtida por secagem. Boletim CEPPA, v.23, n.2, p.221-230, 2005.

GRABNITZ, F.; STAUDENBAUER, W.L. - Characterization of two $\beta$-glucosidase genes from Clostridium thermocellum. Biotechnology Letters, v.10, p. 73-78, 1988.

HOLKER, U.; HÖFER, M.; LENZ, J. - Biotechnological advantages of laboratory scale solidstate fermentation with fungi. Applied Microbiology and Biotechnology, Berlin, v. 64, p. 175186, 2004.

IWASHITA, K.; TODOROKI, K.; KIMURA, H.; SHIMOI, H.; ITO, K. - Purification and characterization of extracellular and cell wall bound $\beta$-glucosidases from Aspergillus kawachii. Bioscience, Biotechnology and Biochemistry, v. 62, n. 10, p. 1938-1946, 1998.

KARNCHANATAT, A.; PETSOM, A.; SANGVANICH, P.; PIAPHUKIEW, J.; WHALLEY, A.J.; REYNOLDS, C.D.; SIHANONTH, P. - Purification and biochemical characterization of an extracellular beta-glucosidase from the wood-decaying fungus Daldinia eschscholzii (Ehrenb.:Fr.) Rehm. FEMS Microbiology Letters, v. 270, p. 162-170, 2007.

MAHESHWARI, R.; BHARADWAJ. G.; BHAT, M.K. - Thermophilic fungi: their physiology and enzymes. Microbiology and Molecular Biology Reviews, v. 64, p. 461-488, 2000.

MANASFIELD, A.K.; ZAECKLEIN, B.W.; WHITON, R.S. - Quantification of glucosidase activities in selected strains of Brettanomyces bruxellensis and Oenococcus oeni. American Journal of Enology and Viticulture, v.53, p.303 -307, 2001.

MATSUURA M, SASAKI J, MURAO S. - Studies on $\beta$-glucosidase that hydrolyze daidzin and genistin: isolation and characterization of an isozyme. Bioscience, Biotechnology and Biochemistry, v. 59, p.1623-1627, 1995.

OH, K.; HAMADA, K.; SAITO, M.; LEE, H.; MATSUOKA, H..- Isolation and properties of an extracellular $\beta$-glucosidase from a filamentous fungus, Cladosporium resinae, isolated from kerosene, Bioscience, Biotechnology and Biochemistry, 1999, v. 63, n. 2, p. 281-287.

PALMERI, R.; SPAGNA, G. - $\beta$-Glucosidase in cellular and acellular form for winemaking application. Enzyme Microbiology andTechnology, v. 40, n. 3, p. 382-389, 2007.

PANDEY, A. - Solid state fermentation. Biochemical Engineering Journal, v.13, p.81-84, 2003.

PANDEY, M.; MISHRA, S. - Expression and characterization of Pichia etchellsii $\beta$-glucosidase in Escherichia coli. Gene, v. 190, n. 1, p. 45-51, 1997. 
PARK, Y.K.; ALENCAR, S.M.; NERY, I.A.; AGUIAR, C.L.; PACHECO, T.A.R.C.Enrichment of isoflavone aglycones in extracted soybean isoflavones by heat and fungal $\beta$ glucosidase. Food and Science Industry, v. 34, n. 4, p. 14-19, 2001.

PARK, Y. K.; AGUIAR, C. L.; ALENCAR, S. M.; MASCARENHAS, H. A. A.; SCAMPARINI, A. R. P. - Conversão de malonil-beta-glicosil isoflavonas em isoflavonas glicosiladas presentes em alguns cultivares de soja brasileira. Ciência e Tecnologia de Alimentos, v. 22, n. 2, p. 130-135, 2002.

PARRY, N.J.; BEEVER, D.E.; OWEN, E.; VANDENBERGHE, I.; BEEUMEN, J.V.; BHAT, M.K. - Biochemical characterization and mechanism of action of a thermostable $\beta$-glucosidase purified from Thermoascus aurantiacus. Biochemistry Journal, v. 353, p. 117-127, 2001.

RUTZ, F.; TORERO,A.; FILER, K. - Fermentação em estado sólido: a evolução na produção das enzimas, Revista Aveworld, v.29, 2008.

YUN, S.; JEONG, C.; CHUNG, D. CHOI, H. - Purification and some properties of a betaglucosidase from Trichoderma harzianum type C-4. Bioscience, Biotechnology and Biochemistry, v. 65, n. 9, p. 2028-2032, 2001. 